\title{
PEMBENTUKAN TUNAS DARI BIJI MANGGIS (Garcinia mangostana L.) ASAL BENGKALIS DENGAN PENAMBAHAN BAP DAN MADU SECARA IN VITRO
}

\section{THE FORMATION OF SHOOTS FROM MANGOSTEEN (Garcinia mangostana L.) SEED FROM BENGKALIS WITH THE ADDITION BAP AND HONEY IN VITRO}

\author{
Mayta Novaliza Isda*, Siti Fatonah, Lia Novita Sari \\ Jurusan Biologi FMIPA Universitas Riau, Kampus Binawidya Pekanbaru, 28293, Indonesia
}

*Corresponding author: maytaisda@yahoo.com

Naskah Diterima: 8 Agustus 2016; Direvisi: 11 Agustus 2016; Disetujui: 23 Oktober 2016

\begin{abstract}
Abstrak
Garcinia mangostana L. merupakan salah satu spesies dari famili Guttiferae kaya senyawa dari golongan xanthon. Manggis memiliki juvenil yang lama. Salah satu metode yang dapat memecahkan masalah dalam perbanyakan tanaman manggis dalam jumlah yang banyak, bisa sepanjang musim dan menghasilkan tanaman yang seragam yaitu kultur in vitro. Tujuan dari penelitian ini adalah untuk menentukan konsentrasi terbaik antara Benzil Amino Purin (BAP) dan madu terhadap induksi tunas dari eksplan biji manggis yang belah tiga melintang secara in vitro. Penelitian ini menggunakan Rancangan Acak Lengkap (RAL) dengan perlakuan BAP $(0 ; 3 \mathrm{mg} / \mathrm{L})$ dan madu $(3 ; 6 \mathrm{mg} / \mathrm{L})$ pada media MS (Murashige-Skoog) dengan pengamatan 70 hari setelah tanam (hst). Hasil penelitian menunjukkan bahwa pemberian BAP maupun madu mampu meningkatkan pembentukan tunas. Pemberian BAP dan madu berpengaruh nyata terhadap persentase terbentuknya tunas, waktu muncul tunas, jumlah tunas dan panjang tunas. Jumlah tunas terbanyak terdapat pada perlakuan $3 \mathrm{mg} / \mathrm{L}$ BAP sebanyak 20 tunas per biji. Kombinasi perlakuan dengan penambahan $3 \mathrm{mg} / \mathrm{L}$ $\mathrm{BAP}+3 \mathrm{ml} / \mathrm{L}$ madu menghasilkan persentase terbentuk tunas tertinggi (100\%); waktu muncul tunas tercepat $12,75 \mathrm{hst}$; dan panjang tunas tertinggi $1,86 \mathrm{~cm}$. Pada penelitian ini telah berhasil menginduksi tunas dari biji manggis yang dibelah tiga melintang asal Bengkalis dengan penambahan BAP dan madu.
\end{abstract}

Kata kunci: BAP; Bengkalis; Induksi tunas; Madu

\begin{abstract}
Garcinia mangostana $L$. is one of the species within the family Guttiferae that rich in compounds from the class of xanthon. Mangosteen has time juvenile problems. One method that can solve the problem in the mangosteen plant propagation which can be produced in a large number in all season and uniform is in vitro culture. The purpose of this study was to determine the best concentration of BAP and honey to induce the formation of shoot from explants of mangosteen seeds split transversely into three pieces by in vitro method. This study used a Completely Randomized Design (CRD) with a treatment of BAP $(0 ; 3 \mathrm{mg} / \mathrm{L})$ and honey $(3 ; 6 \mathrm{mg} / \mathrm{L})$ on MS medium with 70 days of observation. The results showed that the BAP and honey can improve the formation of shoots. The addition of BAP and honey significantly affected the percentage of the formed shoots, the period of shoots appear, the number of shoots and shoot length. The treatment of 3 $\mathrm{mg} / \mathrm{L} B A P$ resulted in the most shoots formed as many as 20 shoots per seed. The combined treatment $3 \mathrm{mg} / \mathrm{L}$ $B A P+3 \mathrm{ml} / \mathrm{L}$ of honey produced 100\% of the formed shoots; fastest period of shoots appear (12.75 DAS); and the longest shoot $(1.86 \mathrm{~cm})$. Therefore, the addition of BAP and honey to the three transversely-split mangosteen seeds from Bengkalis origin successfully induced the formation of the shoot.
\end{abstract}

Keywords: BAP; Bengkalis; Honey; Shoot induction

Permalink/DOI: http//:dx.doi.org/10.15408/kauniyah.v9i2.3376

Copyright $(\mathcal{C}$ 2016, AL-KAUNIYAH: Journal of Biology,

P-ISSN: 1978-3736, E-ISSN: 2502-6720 


\section{PENDAHULUAN}

Manggis (Garcinia mangostana L.) merupakan salah satu buah tropis dengan julukan Queen of Tropical Fruit. Buah manggis mengandung nilai gizi yang sangat banyak. kandungan pericarp kaya akan senyawa dari golongan xanthon dan senyawa yang paling aktif yaitu $\alpha$ mangostin, $\gamma$ mangostin, dan garsinon-E (Nugroho, 2013). Tanaman ini juga merupakan komoditas ekspor yang terus mengalami peningkatan dari tahun ke tahun. Tahun 2006 ekspor manggis sebesar 5,6 juta ton dengan nilai 3,6 juta US\$ dan pada tahun 2012 mencapai 20,1 juta ton dengan nilai 17,4 juta US\$ (Departemen Pertanian, 2012).

Banyak kendala dalam pembibitan tanaman manggis seperti produksi biji layak tanam yang rendah, sifat biji rekalsitran (Qosim, 2004), pertumbuhan sangat lambat, lemah dan perakaran yang sangat sedikit (Harahap et al., 2014). Salah satu teknologi perbanyakan yang menjadi solusi yang dapat memecahkan masalah kekurangan bibit manggis yaitu dengan teknik kultur in vitro karena dapat menyediakan bibit dalam jumlah banyak, seragam dan tidak tergantung musim.

Kultur in vitro yang menggunakan media MS dan penambahan BAP telah banyak dilaporkan. Penambahan $3 \mathrm{mg} / \mathrm{L}$ BAP menghasilkan jumlah tunas tertinggi untuk biji manggis asal Bengkalis yang dibelah dua sebesar 1,55 tunas (Isda et al., 2015). Menurut Harahap et al., (2012), pemberian $5 \mathrm{mg} / \mathrm{L}$ BAP menghasilkan jumlah tunas terbanyak sebesar 11,8 tunas. Selanjutnya Sirchl et al., (2008) menyatakan pemberian $20 \mathrm{mg} / \mathrm{L}$ BAP yang dikombinasikan dengan $10 \mathrm{mg} / \mathrm{L} \quad \mathrm{NAA}$ menghasilkan jumlah tunas tertinggi sebesar 9,5 tunas. Roostika et al., (2008) menyatakan bahwa pemberian $3 \mathrm{mg} / \mathrm{L}$ BAP mampu meningkatkan multiplikasi tunas ketiak.

Modifikasi media dapat dilakukan dengan menambahkan senyawa organik lain untuk meningkatkan pertumbuhan tunas tanaman secara in vitro. Penambahan bahan organik membantu dalam proses pertumbuhan dan perkembangan biji dan regenerasi planlet (Tawaro et al., 2008), membantu proses pembentukan tunas dan daun (Akter et al.,
2007) dan juga meningkatkan ukuran embrio somatik (Al-Khateeb, 2008). Madu dapat digunakan sebagai senyawa organik tambahan. Madu mengandung air dan karbohidrat. Madu mengandung beberapa mineral seperti magnesium, posfor, kalsium dan potassium (Bagde et al., 2013), selain itu juga mengandung beberapa vitamin seperti niasin, asam askorbat, asam pantotenat dan riboflavin (Ajibola et al., 2012).

Penelitian Sari et al., (2011) mengkulturkan bagian batang dan tunas pucuk tanaman Grammatophyllum speciosum BL. dengan penambahan $6 \mathrm{ml} / \mathrm{L}$ madu Al Shifa pada media MS menghasilkan rata-rata jumlah tunas paling banyak (1,08 tunas), tinggi tunas $(26,58)$ dan rata-rata jumlah daun $(4,43)$. Penelitian ini bertujuan untuk menentukan konsentrasi BAP dan madu yang optimal pada media MS dalam menginduksi tunas eksplan biji manggis yang dibelah tiga secara melintang.

\section{MATERIAL DAN METODE}

Penelitian ini akan dilaksanakan pada bulan November 2015 sampai Maret 2016 di Laboratorium Biologi Terpadu Jurusan Biologi Fakultas Matematika dan Ilmu Pengetahuan Alam Universitas Riau Jl. H.R Soebrantas KM. 12,5 Panam, Pekanbaru. Bahan tanaman yang digunakan adalah biji dari buah yang masak asal Bengkalis. Buah yang sudah masak diambil dari pohon kemudian diambil bijinya dengan cara dibersihkan daging buahnya. Selanjutnya disterilisasi di dalam laminar air flow berturut-turut menggunakan larutan $\mathrm{Na}$ hipoklorit $20 \%$ + Tween-80 selama 10 menit dan disterilisasi dengan alkohol $70 \%$ selama 5 menit. Setiap pergantian larutan sterilisasi dibilas dengan akuades sebanyak 3 kali. Biji diletakkan dalam cawan petri yang berisi campuran larutan akuades dan iodin kemudian dibelah menjadi tiga bagian secara melintang.

Penelitian ini menggunakan Rancangan Acak Lengkap (RAL). Konsentrasi BAP dan madu yang digunakan terdiri dari 6 taraf perlakuan, yaitu: M1 (0 mg/L atau kontrol); M2 (3 mg/L BAP); M3 (3 ml/L madu); M4 (6 $\mathrm{ml} / \mathrm{L}$ madu $) ; \mathrm{M} 5$ (3 $\mathrm{mg} / \mathrm{L} \mathrm{BAP}+3 \mathrm{ml} / \mathrm{L}$ madu); M6 (3 mg/L BAP + $6 \mathrm{ml} / \mathrm{L}$ madu). 
Parameter dalam penelitian meliputi: persentase eksplan hidup (\%), persentase pembentukan tunas (\%) waktu muncul tunas (hst), jumlah tunas (buah), panjang tunas (cm) dan jumlah daun (helai). Data hasil pengamatan selanjutnya dianalisis menggunakan Analysis of Variance (ANOVA). Jika terjadi pengaruh nyata dilakukan dengan uji Duncan's Multiple Range Test (DMRT) pada taraf kepercayaan 5\% dengan menggunakan aplikasi SPSS.

\section{HASIL \\ Persentase Eksplan Hidup dan Pemben- tukan Tunas}

Hasil penelitian yang dilakukan terhadap eksplan biji manggis yang dibelah tiga bagian secara melintang pada media $\mathrm{Mu}$ rashige-Skoog (MS). Pemberian konsentrasi zat pengatur tumbuh BAP dan madu baik tunggal maupun kombinasi secara in vitro pada hari ke-70 hst, didapatkan hasil yang terlihat pada Tabel 1.

Tabel 1. Persentase eksplan hidup dan pembentukan tunas pada 70 hari setelah tanam

\begin{tabular}{ccccc}
\hline \multirow{2}{*}{ Kode Perlakuan } & \multicolumn{3}{c}{ Perlakuan } & \multicolumn{2}{c}{ Persentase } \\
\cline { 2 - 5 } & BAP (mg/l) & Madu $(\mathrm{ml} / \mathrm{l})$ & Eksplan hidup & Pembentukan tunas \\
\hline M1 & - & - & 100 & $25, .00^{\mathrm{a}}$ \\
M2 & 3 & - & 100 & $83,33^{\mathrm{b}}$ \\
M3 & - & 3 & 100 & $16,67^{\mathrm{a}}$ \\
M4 & - & 6 & 100 & $16,67^{\mathrm{a}}$ \\
M5 & 3 & 3 & 100 & $100,00^{\mathrm{b}}$ \\
M6 & 3 & 6 & 100 & $83,33^{\mathrm{b}}$ \\
\hline
\end{tabular}

Keterangan: Angka yang diikuti oleh huruf yang berbeda pada kolom yang sama menunjukkan berpengaruh nyata $(\mathrm{P}>0,05)$ pada uji DMRT taraf 5\%

Tabel 2. Rata-rata pertumbuhan tunas eksplan biji manggis terhadap penambahan BAP dan madu pada 70 hari setelah tanam

\begin{tabular}{ccccccc}
\hline & \multicolumn{2}{c}{ Perlakuan } \\
Kode & \multicolumn{7}{c}{ Parameter Pengamatan } \\
\cline { 2 - 6 } Perlakuan & $\begin{array}{c}\text { BAP } \\
(\mathrm{mg} / \mathrm{l})\end{array}$ & $\begin{array}{c}\text { Madu } \\
(\mathrm{ml} / \mathrm{l})\end{array}$ & $\begin{array}{c}\text { Waktu Muncul } \\
\text { Tunas } \pm \text { sd } \\
(\text { Hari })\end{array}$ & $\begin{array}{c}\text { Jumlah Tunas } \\
\pm \text { sd (Buah) }\end{array}$ & $\begin{array}{c}\text { Panjang } \\
\text { Tunas } \pm \text { sd } \\
(\mathrm{cm})\end{array}$ & $\begin{array}{c}\text { Jumlah } \\
\text { Daun } \pm \text { sd } \\
(\text { Helai })\end{array}$ \\
M1 & - & - & $61,25^{\mathrm{d}}$ & $1,25^{\mathrm{a}}$ & $0,30^{\mathrm{a}}$ & 0,00 \\
M2 & 3 & - & $27,50^{\mathrm{b}}$ & $20,00^{\mathrm{b}}$ & $1,00^{\mathrm{a}}$ & 1,50 \\
M3 & - & 3 & $69,50^{\mathrm{d}}$ & $0,75^{\mathrm{a}}$ & $0,53^{\mathrm{a}}$ & 0,00 \\
M4 & - & 6 & $66,50^{\mathrm{d}}$ & $0,75^{\mathrm{a}}$ & $0,35^{\mathrm{a}}$ & 0,00 \\
M5 & 3 & 3 & $12,75^{\mathrm{a}}$ & $14,25^{\mathrm{b}}$ & $1,86^{\mathrm{b}}$ & 1,75 \\
M6 & 3 & 6 & $40,50^{\mathrm{c}}$ & $14,25^{\mathrm{b}}$ & $0,76^{\mathrm{a}}$ & 2,00 \\
\hline
\end{tabular}

Keterangan: Angka yang diikuti oleh huruf yang berbeda pada kolom yang sama menunjukkan berpengaruh nyata $(\mathrm{P}>0,05)$ pada uji DMRT taraf $5 \%$

Pada Tabel 1 menunjukkan penambahan madu dapat meningkatkan persentase hidup eksplan pada 70 hst mencapai 100\%. Eksplan yang hidup ini dipengaruhi oleh beberapa faktor antara lain kondisi fisiologis eksplan, umur eksplan dan ukuran eksplan. Umur dan ukuran eksplan mempengaruhi cadangan makanan yang terkandung dalam biji, selain itu juga mempengaruhi tingkat kematangan embrio.
Menurut Sutopo (2002), biji yang berukuran besar dengan bobot yang berat memiliki cadangan makanan yang lebih banyak dibandingkan dengan biji yang berukuran kecil dan bobot yang ringan. Isda et al. (2015) menyatakan bahwa viabilitas eksplan yang berbeda dipengaruhi oleh tingkat kematangan biji karena kondisi fisiologis biji mempengaruhi cadangan makanan dan komposisi embrio didalam biji. 


\section{Pertumbuhan Tunas Manggis}

Hasil ANOVA menunjukkan bahwa pemberian zat pengatur tumbuh BAP dan ma$\mathrm{du}$ baik tunggal maupun kombinasi berpengaruh nyata terhadap parameter waktu muncul tunas dan tidak berpengaruh nyata terhadap jumlah daun. Perlakuan BAP dan madu hanya berpengaruh nyata terhadap jumlah tunas dan panjang tunas dari eksplan biji manggis. Ratarata dan hasil uji lanjut terlihat pada Tabel 2.

Pemberian BAP dan madu berpengaruh terhadap jumlah tunas yang dihasilkan. Jumlah tunas terbanyak terdapat pada perlakuan 3 mg/L BAP sebanyak 20,00 buah dan jumlah tunas terendah sebesar 0,75 buah pada perlakuan madu tunggal dan tidak berbeda nyata dengan perlakuan kontrol (Gambar 1).

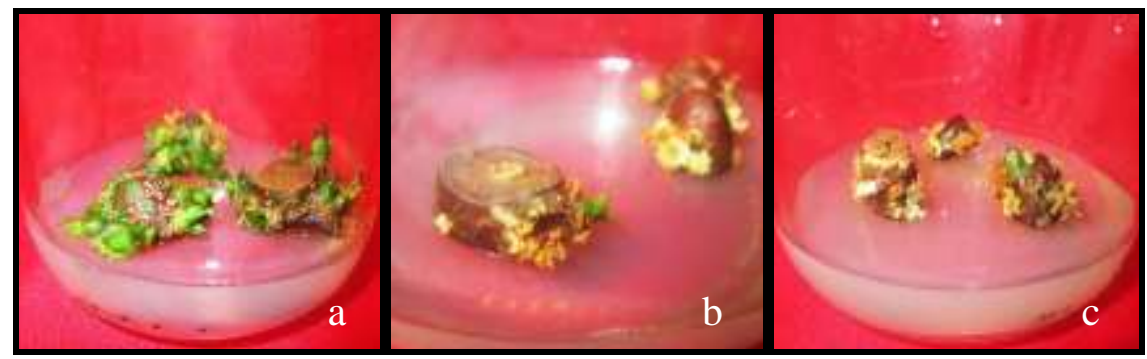

Gambar 1. Pembentukan tunas manggis dengan tipe pembelahan eksplan secara melintang pada 70 hst (a) tunas terbanyak pada perlakuan $3 \mathrm{mg} / \mathrm{L}$ BAP, (b) tunas sedikit pada perlakuan $6 \mathrm{ml} / \mathrm{L}$ madu, (c) pembentukan tunas pada perlakuan kontrol

\section{PEMBAHASAN}

\section{Persentase Eksplan Hidup dan Pem- bentukan Tunas}

Kandungan nutrisi dalam media juga mempengaruhi tingkat persentase hidup eksplan. Adanya penambahan madu pada konsentrasi tertentu diduga meningkatkan kandungan nutrisi yang cukup untuk pertumbuhan eksplan. Madu mengandung beberapa mineral seperti sodium, kalsium, magnesium, potassium, posfor, seng, dan zat besi (Bogdanov et al., 2008). Madu mengandung beberapa vitamin seperti riboflavin, niasin, asam pentotenat dan asam askorbat (Bagde et al., 2013). Madu juga mengandung sakarida, protein, enzim, asam amino dan asam organik (Manyi-Loh et al., 2011).

Hasil penelitian menunjukkan bahwa penambahan BAP dan madu tunggal maupun yang kombinasi berpengaruh terhadap persentase terbentuk tunas. Penambahan 3 $\mathrm{mg} / \mathrm{L}$ BAP yang dikombinasikan dengan 3 $\mathrm{ml} / \mathrm{L}$ madu menghasilkan persentase terbentuk tunas terbanyak mencapai $100 \%$ dan penambahan madu tunggal menghasilkan persentase terbentuk tunas terendah sebesar $16,67 \%$. Penambahan madu yang dikombinasikan dengan BAP mampu meningkatkan persentase jumlah tunas dibandingkan dengan perlakuan tunggal. Hal ini diduga karena hormon endogen pada eksplan belum mencukupi untuk meningkatkan persentase terbentuknya tunas sehingga perlu penambahan hormon sitokinin pada media. Penambahan BAP yang dikombinasikan dengan madu pada konsentrasi yang tinggi menyebabkan tekanan osmotik media menjadi tinggi sehingga mengganggu dalam proses penyerapan unsur hara dan hormon eksogen sehingga mengganggu pertumbuhan eksplan. Menurut Sari et al. (2011) madu mengandung senyawa organik tambahan yang dapat berinteraksi dengan hormon endogen pada tanaman sehingga dapat menginduksi terbentuknya tunas.

\section{Pertumbuhan Tunas Manggis}

Pada hasil penelitian pemberian BAP dan madu baik tunggal maupun kombinasi berpengaruh terhadap waktu munculnya tunas eksplan biji manggis. Pemberian BAP pada konsentrasi $3 \mathrm{mg} / \mathrm{L}$ yang dikombinasikan dengan $3 \mathrm{ml} / \mathrm{L}$ madu menghasilkan waktu muncul tunas tercepat pada 12,75 hst, sedangkan pemberian $3 \mathrm{ml} / \mathrm{L}$ madu tunggal menghasilkan waktu muncul tunas terlama pada 69,50 hst dan tidak berbeda nyata dengan perlakuan kontrol dan $6 \mathrm{ml} / \mathrm{L}$ madu tunggal. Hal ini diduga karena hormon endogen yang 
terdapat pada eksplan belum mampu pempercepat pembentukan tunas sehingga perlu penambahan hornon sitokinin eksogen untuk mempercepat pembentukan tunas.

Pemberian BAP yang dikombinasikan dengan $3 \mathrm{ml} / \mathrm{L}$ madu mampu menghasilkan waktu muncul tunas tercepat. Hal ini diduga karena penambahan $3 \mathrm{ml} / \mathrm{L}$ madu mampu mempercepat terbentuknya tunas. Hasil penelitian ini lebih cepat jika dibandingkan dengan hasil penelitian Isda et al., (2016) waktu pembentukan tunas paling cepat dari eksplan biji manggis asal Bengkalis pada 1,55 hst pada dengan penambahan $1 \mathrm{mg} / \mathrm{L}$ BAP. Perbedaan respon in vitro ini juga dipengaruhi oleh tingat kemiripan genetik yang rendah, walaupun manggis termasuk tanaman apomiksis, namun terjadi variasi genetik dengan tingkat kemiripan yang berbeda-beda.

Menurut Triatminingsih (2008), konsentrasi ZPT merupakan faktor penting dalam keberhasilan diferensiasi pertumbuhan dari kultur in vitro. Pemberian BAP dan madu berpengaruh terhadap panjang tunas yang dihasilkan. Panjang tunas tertinggi terdapat pada perlakuan $3 \mathrm{mg} / \mathrm{L}$ BAP yang dikombinasikan dengan $3 \mathrm{ml} / \mathrm{L}$ madu sebesar 1,86 $\mathrm{cm}$ dan panjang tunas terendah sebesar $0,30 \mathrm{~cm}$ pada perlakuan kontrol. Hal ini diduga karena pemberian madu $3 \mathrm{ml} / \mathrm{L}$ mampu menyediakan sumber karbon yang mencukupi untuk partumbuhan panjang eksplan. Hasil penelitian ini lebih rendah dibandingkan dengan penelitian Isda et al., (2016) menghasilkan panjang tunas sebesar 5,10 $\mathrm{cm}$ pada perlakuan $3 \mathrm{mg} / \mathrm{L} \mathrm{BAP} \mathrm{+}$ $3 \mathrm{ml} / \mathrm{L}$ madu. Menurut Joni et al., (2014), kandungan nitrogen yang tinggi pada media MS akan menginduksi terbentuknya hormon sitokinin pada eksplan yang akan memicu pembelahan sel sehingga banyak terbentuk tunas, namun elongasi tunas menjadi terhambat.

Hasil penelitian menunjukkan bahwa pemberian BAP dan madu tidak berpengaruh terhadap jumlah daun yang dihasilkan. Namun pemberian $3 \mathrm{mg} / \mathrm{L}$ BAP yang dikombinasikan dengan $6 \mathrm{ml} / \mathrm{L}$ madu cenderung menghasilkan jumlah daun terbanyak sebesar 2 daun. Namun pemberian madu tunggal dan kontrol belum membentuk daun tetapi pada perlakuan ini lebih banyak membentuk kalus dan tunas yang terbentuk belum memperlihatkan pembentukan daun hanya membentuk tonjolan bakal tunas. Rata-rata jumlah daun yang dihasilkan dalam penelitian ini relatif rendah. Hal ini disebabkan oleh kebanyakan tunas yang terbentuk tidak memiliki daun, diduga karena adanya persaingan dalam penyerapan unsur hara pada media. Tidak terbentuknya akar pada tunas mempengaruhi penyerapan unsur hara untuk pembentukan daun. Tunas-tunas yang terbentuk perlu dilakukan subkultur untuk melanjutkan regenerasi tanaman dalam pembentukan daun.

\section{KESIMPULAN}

Jumlah tunas terbanyak terdapat pada perlakuan $3 \mathrm{mg} / \mathrm{L}$ BAP sebanyak 20 tunas per biji. Kombinasi perlakuan dengan penambahan $3 \mathrm{mg} / \mathrm{L} \mathrm{BAP}+3 \mathrm{ml} / \mathrm{L}$ madu menghasilkan persentase terbentuk tunas terbanyak (100\%); waktu muncul tunas tercepat $12,75 \mathrm{hst}$; dan panjang tunas tertinggi $1,86 \mathrm{~cm}$.

\section{UCAPAN TERIMA KASIH}

Terimakasih kepada Kementrian Riset, Teknologi dan Pendidikan Tinggi atas Grant DRPM dengan Nomor surat kontrak 135/SP2H/LT/DRPM/III/2016.

\section{REFERENSI}

Ajibola, A, Chamunorwa, J. P. \& Erlwanger, K. H. (2012). Nutraceutical values of natural honey and its contribution to human health and wealth. Nutrition \& Metabolism, 9 (61), 1-12.

Akter, S., Nasiruddin, K. M., \& Khaldun, A. B. M. (2007). Organogenesis of Dendrobium orchid using traditional media and organic extracts. Jurnal of Agriculture and Rural Development, 5 (1\&2), 30-35.

Al-Khateeb, A. A. (2008). Regulation of in vitro bud formation of date palm (Phoenix dactylifera 1.) Cv. Khanezi by different carbon sources. Bioresource Technology, 99 (14), 6550-6555.

Bagde, A. B., Sawant, R. S., Bingare, S. D., Sawai, R. V., \& Nikumbh, M. B. (2013). Therapeutic and nutritional values of honey (madhu). International Research Journal of Pharmacy, 4 (3), 19-22. 
Bogdanov, S. T., Jurendic, R. Sieber, P. Gallmann. 2008. Honey for nutrition and health: a Review. American Journal of The College of Nutrition, 27, 677-689.

Departemen Pertanian. 2012. (2015 September 3). Retrived from http://database.deptan. go.id.

Harahap, F., Hasratuddin, \& Suriani, C. (2012). Shoot growth of in vitro mangosteen (Garcinia mangostana 1.) Results of benzyl adenine plant growth regulators and the different explants size. Saintika Journal, 12, 1-13.

Harahap, F., Poerwanto, P., Suharsono, Suriani, C., \& Rahayu, S. (2014). In vitro growth and rooting of mangosteen (Garcinia mangostana 1.) on medium with different concentration of plant growth regulator. HAYATI Journal of Biociences, 21 (4), 151-158.

Isda, M. N., Fatonah, S., \& Rahmawati, R. Y. (2015). Induksi tunas dari eksplan biji manggis (Garcinia mangostana L.) asal Bengkalis secara in vitro proceeding Semirata. Pontianak.

Joni, Y. Z., Efendi, D., \& Roostika, I. (2014). Morfogenesis eksplan keping biji dari tiga klon manggis (Garcinia mangostana L.) pada tiga jenis media dasar. Journal Horticulture, 24 (2), 94-101.

Manyi-Loh, C. E., Clarke, A.M., \& Ndip, R. N. (2011). An overview of honey: therapeutic properties and contribution in nutrition and human health. African Journal of Microbiology Research, 5 (8), 844-852.
Nugroho, A. E. (2013). Manggis (Garcinia mangostana L.): dari kulit buah yang terbuang hingga menjadi kandidat suatu obat [Bibliografi]. Fakultas Farmasi, Universitas Gadjah Mada. Yogyakarta.

Qosim, W. A. (2004). Pemuliaan manggis tak sesulit dibayangkan. (2015 September 7). Retrived from http://www.pikiran-rak yat.com/cetak/1204/cakrawala/lainnya4. html.

Roostika, I., Sumarlim, N., \& Mariska, I. (2008). Micropropagation of mangosteen (Garcinia mangostana L.). Indonesian Journal of Agriculture, 1 (1), 28-33.

Sari, Y. P., Manurung, H., \& Novita, V. (2011). Mikropropagasi tanaman anggrek tebu (Grammatophyllum speciosum bl.) secara in vitro dari sumber eksplan tunas pucuk pada media ms (MurashigeSkoog) dengan penambahan madu. Mulawarman Science, 10, 51-62.

Sirchi, M. H. T., Kadir, M. A., Aziz, M.A., Rashid, A. A., Rafat, A., \& Javadi, M. B. (2008). Amelioration of mangosteen mikropropagation through leaf and seed segments (Garcinia mangostana L.). African Journal of Biotechnology, 7 (12), 2025-2029.

Tawaro, S., Suraninpong, P., \& Chanprame, S. (2008). Germination and regeneration of Cymbidium findlaysonianum lindl. On a medium supplemented with some organic sources. Walailak Journal Science and Technology, 5 (2), 125-135. 